\title{
The transient changing of forces in interrupted milling
}

\author{
Z. Pálmai ${ }^{1} \cdot$ J. Kundrák ${ }^{1} \cdot$ T. Makkai $^{1}$
}

Received: 11 October 2018 / Accepted: 26 June 2019/Published online: 19 July 2019

(C) The Author(s) 2019

\begin{abstract}
The knowledge of cutting force in practical technology is increasingly important due to the growing quality and performance requirements. Therefore, especially in the case of milling, it also represents an important research area of cutting theory. The aim of the research in the project presented here was the study of transient processes assumed in milling. For this purpose, a model that describes cutting force in interrupted cutting realistically was developed. According to the initial hypothesis, cutting force reaches a stationary status in a finite time due to the fact that the thermodynamic processes of deformation are time consuming. This influences the energy characteristics of cutting significantly in the case of milling. It was assumed that the transient increase of cutting force can be described by a formula where Kienzle's force formula is supplemented by an exponential function. The validation of this force model was performed by force measuring during the machining of normalized C-steel of C45 quality. One tool insert was used in the face milling tool. The measurements justified the applicability of the model; the Pearson index of the correlation was $R^{2}>0.9$, moreover, it was higher than 0.95 in many cases.
\end{abstract}

Keywords Cutting $\cdot$ Transient force $\cdot$ Milling modeling

\section{Introduction}

Bayard, O. [1] listed 48 models through which the researchers of cutting theory wanted to describe chips formation and the accompanying mechanical and thermal processes. We can also add further researches which studied the formation of sheared chips using thermoplastic instability or fracture mechanics (see e.g., Komanduri et al. [2]) or hard turning, which is currently the subject of extensive research (e.g., Kundrák et al. [3]), as well as the extensive literature on interrupted cutting and milling. Thus, the otherwise interesting fact that cutting has been the continuous interest of the researchers of machining for about 150 years can be understood. Based on the above, two statements can certainly be made. One is that strong industrial interests are attached to these researches, and the second is that the seemingly simple technology comprises complicated processes.

This can be perceived in the summarizing work in which Cheng et al. [4] discuss machining dynamics in a

Z. Pálmai

palmayz@t-online.hu

1 Institute of Manufacturing Science, University of Miskolc, Miskolc H-3515, Hungary comprehensive systematic manner. They demonstrate from multiple angles how important the theoretical modeling of multi-body dynamic features of machines and the recognition of these are from the point of view of industrial practice. In turning, in its initial phase in certain special ways of machining, the cutting force varies rapidly [5]; however, milling is characterized by dynamic changes throughout the process [6]. They revealed that not only the shock effect of the cutting force, but also its rapid change strongly influences the stability of the machining system. In his comprehensive review of cutting theory and detailed investigation of milling, Altintas specified that, besides the shock effect of cutting force, its rapid change also influences the process [7].

Solid body physics have become a part of the tool kit of researchers. Turkovich [8] was able to rely on the considerable previous findings in the application of dislocation theory. These were supported by the material structure testing of Black, performed on steel chips by transmission and electron and scanning microscopes [9-12]. There were researchers who investigated the movement of dislocations considering even the atomic structure $[13,14]$ while others studied the impact of the steel structure [15].

Ultimately, the micro-level processes determine the macrolevel behavior of the material. This has led to the broad-scale application of constitutive equations in the plasticity theory or 
the increasingly popular FEM descriptions of chip formation. Essentially, this is a phenomenological method that describes the connection among stress, deformation, the speed of deformation, and temperature developing as a result of the force triggering deformation.

Although significant results have been achieved in the FEM simulation of the process of chip formation, the precision of these simulations raises constant concerns [13]. This must certainly be taken into consideration when cutting force is to be determined. It is important that the constitutive model describing the behavior of the machined material should be applied with correct material properties in calculations. This runs into difficulties that are hard to overcome owing to the significant, fast deformation and heat. Such extreme experimental conditions cannot be produced in material testing; therefore, measurement results need to be extrapolated outside the studied parameter range. This was also established by Zerilli [16] previously.

Several further studies relied on the famous experiment of Salomon [17], on which Longbottom and Lanham wrote a review [18]. We know that cutting temperature develops in a special way in interrupted cutting; it starts to decrease above a maximum value if cutting speed is increased [19, 20]. Based on the findings shown in Fig. 1, it was already known in 1929 that the change of cutting temperature and that of cutting force in interrupted cutting are completely synchronized. Consequently, the relationship is evident; however, the conclusion that the change of cutting force shows the same pattern that was long known with regard to cutting temperature has not been drawn yet. Later, several researchers, such as Crookall et al. [21] and Zheng [22], connected cutting force and temperature. The relationship of these two parameters was proven in face milling. Yet, in spite of the fact that they used the exponential formula of Pálmai [21] in the calculation of cutting temperature, there is no reference to the fact that cutting force should follow the same law.
The experimental findings of Lazoglu et al. [23] in hard turning and Fan et al. [24] in the cutting of a Ti-6Al-4V alloy show the close relationship of the force and temperature that can be measured in cutting. Thandra és Choudhury [25] experienced this when applying an oxy-acetylene hot-machined device under special circumstances.

The same statement can be made with regard to the research by Aurich et al. [26], who performed a 3D FEM analysis, and also regarding the end-milling research findings of Sato et al. [27]. The close relationship between the force and temperature in high- and ultra-high-speed milling was shown by Cui et al. [28] with Abaqus/Explicit FEM software.

As the wear of the tool is determined by force and temperature together, as known, cutting force is used to monitor wear [29]. Suresh et al. [30] studied the relationship of the cutting force and the wear of the tool in hard turning. Li et al. [31] applied the cutting force for the monitoring of the tool wear in a way that they examined the irregular fluctuation of the force.

These examinations did not extend to the transient initial section of chip formation. This was equally ignored in theoretical analyses and in experiments. The initial phase of chip formation is also important from a practical angle since the entire process of milling can be regarded as transient. Zheng et al. [32] showed by the fractal analysis of cutting force and in force measurements registered with a microsecond time scale that the exponential growing phase of the force can be clearly seen beside the chaotic characteristics. This can be concluded from the results obtained by Zhang et al. [33] in hard milling.

So, the change of the cutting process in time has been the subject of intensive research for many years; however, we can conclude that the dynamics of the force's change, which is also significant due to the close connection between temperature and force, has not been dealt with even in the latest publications. This paper discusses the findings of the work which aims to examine the transient, dynamic characteristics occurring in interrupted cutting.
Fig. 1 Synchronicity between cutting force and cutting temperature (Salomon, C. [17])

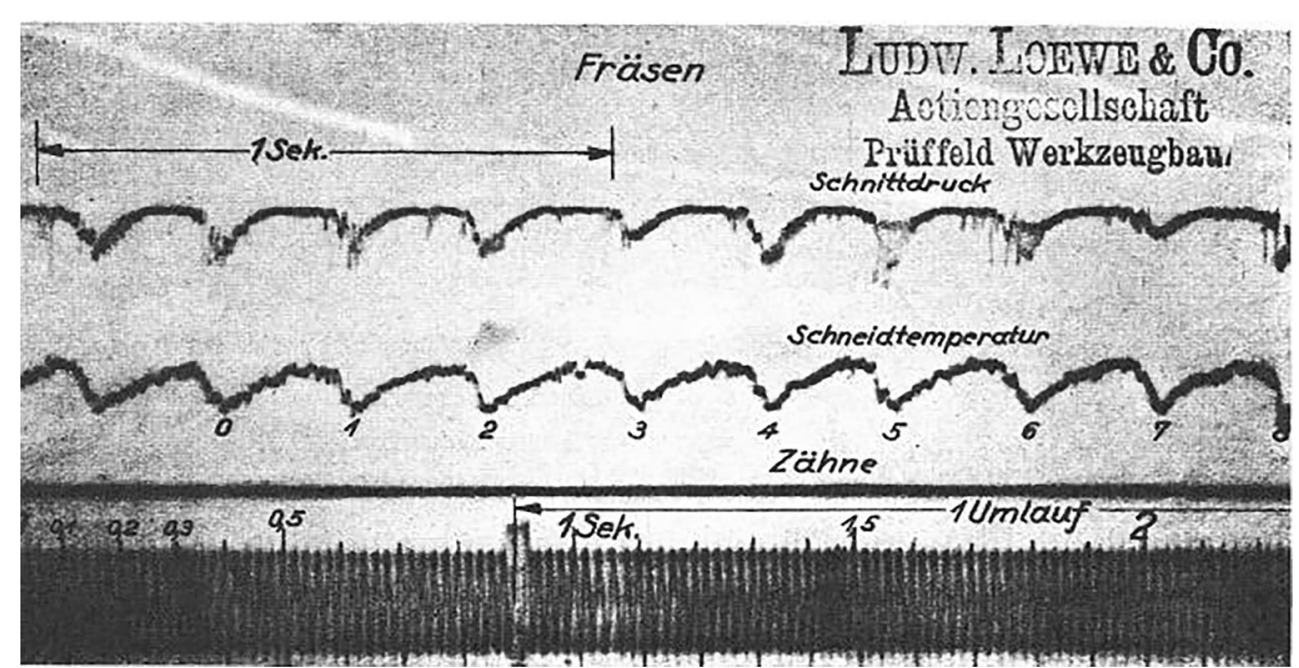




\section{The transient model of cutting force in milling}

The force that is necessary for chip formation is basically determined by the chemical composition, structure, and condition of the workpiece's material. The impacts of significant, fast deformation on the material structure were studied in detail by Zener and Holomon [34, 35] seven decades ago. They described the phenomena that influence the behavior of the material and determine the stress necessary for enforcing the expected deformation. According to Ashby [36], there are at least six distinguishable and independent ways in which a polycrystalline can be deformed and yet remain crystalline: a stress which exceeds the theoretical shear strength, then the glide motion of dislocations, the dislocation creep. Two independent kinds of diffusional flow originate from the flow of point defects through grains and round their boundaries: Nabarro-Herring creep and Coble creep. Finally, twinning provides a sixth mechanism.

Although not all of these can be shown in cutting, the process is quite complex. In Fig. 2, a C-steel chip root where the two characteristic zones of deformation appear can be seen. The difference between the two zones is striking.

The little pegs that can be seen in the lower part of the flow zone (2) deserve special attention. As the chip root was made by removing the tool with a blow in the direction of cutting speed $v_{c}$, these pegs suggest the development of local welding. This was a steel and hard metal material pair and it is obvious that such phenomenon does not happen, e.g., in TiN-coated inserts. Yet it must be concluded that friction speed can even be very small on the contact surface of the tool and the chip, and the internal friction of the flow zone determines the friction force.

The processes are especially complex near the edge of the tool where the two zones meet. Figure 3, in which the rake face of a worn tool can be seen during the turning of C-steel, shows an example for this. The characteristic, chaotic signs of the movement of the material can be seen in the band between the tool edge and the worn crater.

So, the temperature and the deformation are connected in a complex way, in several mechanisms occurring at the same time. Leslie [37] showed that the stress needs to be increased in order to maintain the strain rate. Several processes happen at a time, for example

- the mobile dislocation density increases by the multiplication of the dislocations;

- the average dislocation speed increases very quickly.

These cause a stress that is composed of two parts: one of them is dependent on temperature and the other that is athermal, i.e., independent of temperature. Nevertheless, it is true that the $G$ shear modulus of the material also

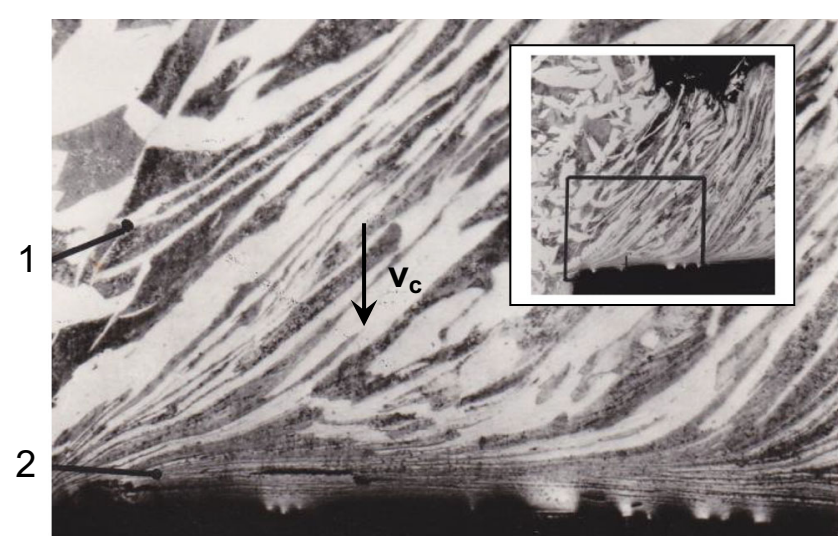

Fig. 2 Steel chip root (C45) made with turning

depends on temperature in the latter. Thus, it can be stated that stress and temperature are closely connected on the level of microstructure. Owing to the difficulties caused by complex processes, Lüthy and Whitte [15] studied the structural phenomenon like grain boundary sliding with a phenomenological method.

Examining the movement of dislocations on an atomic level, Lin et al. [13] concluded that dislocation density has a characteristic of increase that is similar to the charging of an electronic condenser. Similar phenomena occur on a macroscopic scale as well.

The calculations of Kalhori et al. [38], which were performed considering the dislocation density, the deformation localized on the shear zone, strain hardening, and thermal softening, also show the close relationship of temperature and shear stress.

The examination, carried out by Li et al. [39], is typical of the complex material structure characteristics of chip formation. The authors identified the various crystal axles in the chip root, and thus, they identified the significantly varying cutting forces belonging to various directions. It is clear how complicated the actual consideration of crystal structure is even in the case of a single crystal. The micro-structural change or strengthening mechanism have

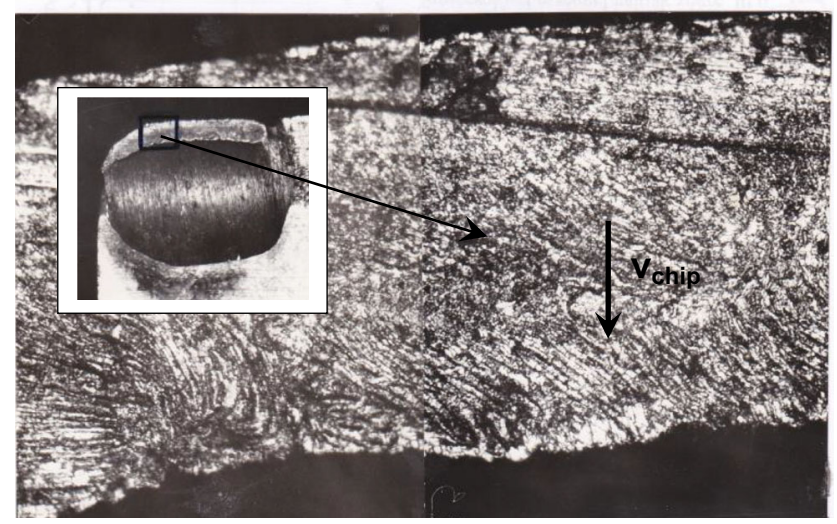

Fig. 3 The rake face of the worn high-speed steel turning tool 
been the subject of intensive research ever since, and the work has not been completed yet.

All these studies show that the significant deformation, the speed of deformation, and the fast thermal processes characteristic of chip formation are also shown in the change of the material structure. As we can see, it became obvious several decades ago that chip formation is characterized by extreme processes, whose physical observation is hindered by great difficulties. The extensive dislocation theory and material structure investigations concentrated on morphological, structural, and energetic features but a lot less attention was dedicated to kinematical characteristics.

It is broadly known that cutting temperature is usually measured at the contact surface of the tool and the chip. Salomon [17] did the same when taking his measurements and the known results were reached. So, the temperature and force analogy can be regarded as directly proven in the flow zone. This can also be established for the shear zone in another temperature range. Here, the important fact that a part of the heat produced flows opposite the direction of the movement of the material must be considered. As a result of this, the temperature of the material arriving at the shear zone changes rapidly at the beginning of the operation: it is initially low then starts increasing quickly. This generates a transient phenomenon, which ceases in continuous cutting. There is no time for this in milling, and so the forming stress in the material changes rapidly during the entire machining cycle.

It can be stated clearly that the critical nature of temperature in the deformation processes was also justified by these examinations. Based on the many-sided material studies, it can also be established that the cutting force increases rapidly from the start of the process until it reaches a limit value.

This can be approximated by the

$\frac{\mathrm{dF}}{\mathrm{dt}} \cong C \exp -\frac{t}{\tau}$

empirical equation where $\tau$ is the time constant of the process and $C$ is a technology-dependent constant. The solution of the equation with initial condition $F=F\left(t_{0}=0\right)=0$ becomes

$F=C_{F}\left[1-\exp -\frac{t}{\tau}\right]$

where $C_{F}=C \tau$. This formula is identical with the formula regarding cutting temperature that was derived by Pálmai [21] based on the findings of Salomon [17]. Equation (2) is in line with the other research results published by the researchers of cutting in connection with the nearly adiabatic, fast, significant deformation. The most frequent method of interrupted cutting is milling, where, as known, the undeformed thickness of the band removed by the tool changes, which also influences cutting force. According to the Kienzle's exponent power function mainly used in turning, the specific cutting force is $k_{c}=F / a_{p} f_{z}^{x} \sin ^{x} \varphi$, where $a_{p}$ is depth of cut, $f_{z}$ is feed per tooth (which equals feed per revolution when one insert is used), $x$ is Kienzle's exponent, and $\varphi$ is angle position of the milling cutter. In milling, this specific cutting force, ignoring the other technological parameters, considering Eq. (2) is

$k=C_{k} \sin ^{-x} \varphi\left(1-\exp ^{-} \frac{t}{\tau}\right)=C_{k} \sin ^{-x} \varphi\left(1-\exp -\frac{\varphi}{\varphi_{\tau}}\right)$,

where $C_{k}$ is a constant of specific cutting force, $\varphi=\omega t$, and $\varphi_{\tau}=\omega \tau$ with $\omega$ angular speed. This transient angle $\varphi_{\tau}$ influences function $F(\varphi)$ in the same way as time constant $\tau$, which is indicated by Fig. 4 .

If cutting commences in angle position $\varphi_{0}$ of the milling cutter, the specific cutting force becomes

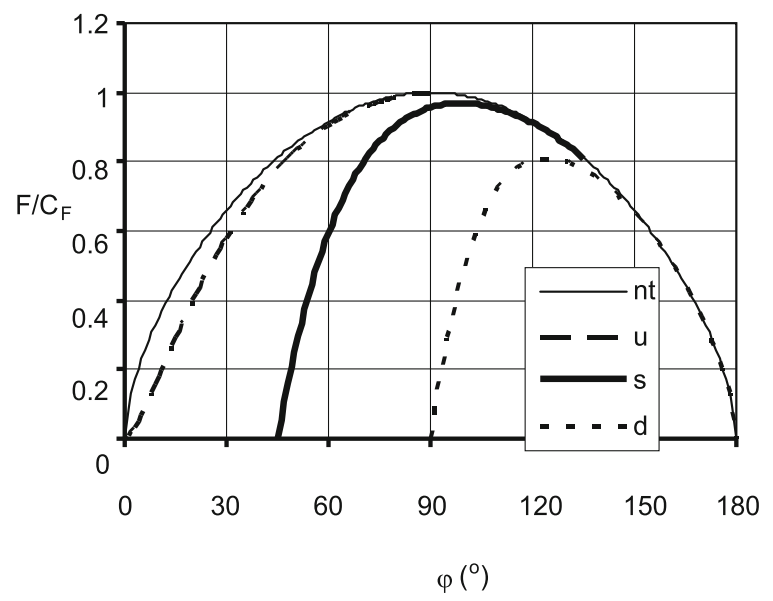

a) As a function of position angle $\varphi$.

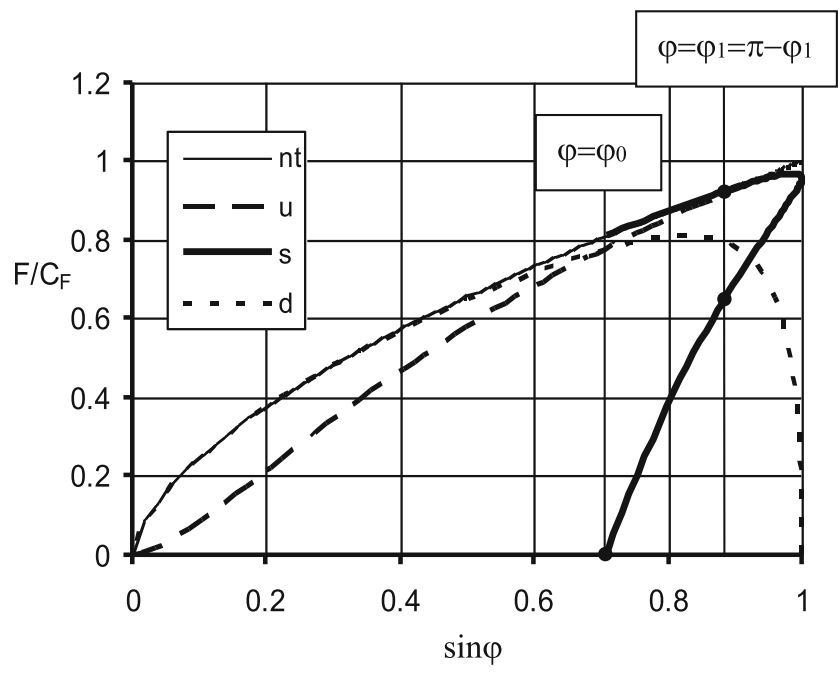

b) As a function of $\sin \varphi$

Fig. 4 Cutting force in various methods of milling. nt, not transient; $u$, up; s, symm; d, down 
Fig. 5 Specific cutting force in various typical methods of milling. nt, not transient; $\mathrm{u}$, up; s, symm; d, down

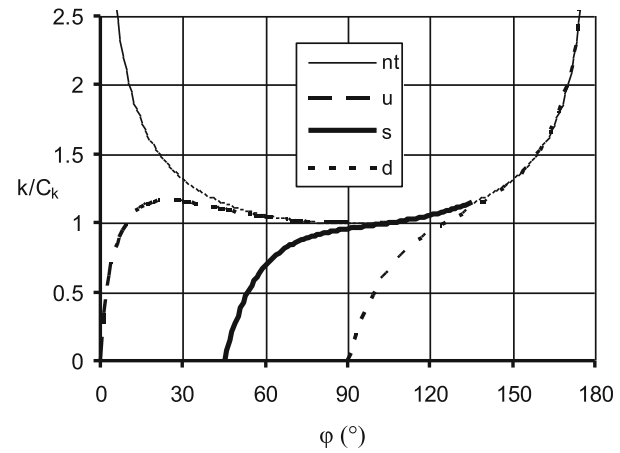

a) As a function of position angle $\varphi$

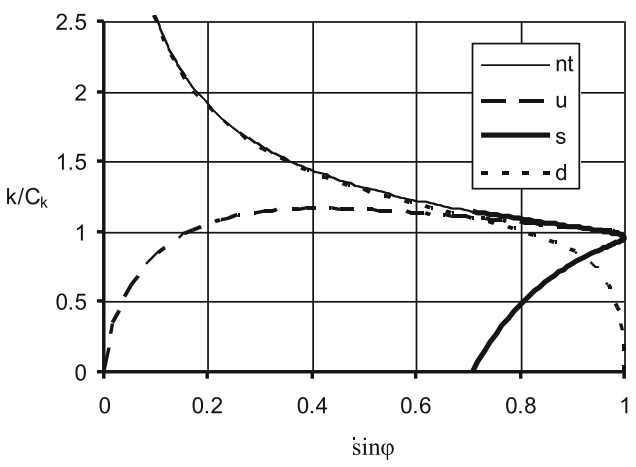

b) As a function of $\sin \varphi$
$k=C_{k} \sin ^{-x} \varphi\left(1-\exp -\frac{\varphi-\varphi_{0}}{\omega \tau}\right)=C_{k} \sin ^{-x} \varphi\left(1-\exp -\frac{\varphi-\varphi_{0}}{\varphi_{\tau}}\right)$,

and the cutting force is

$$
\begin{aligned}
F & =C_{F} \sin ^{1-x} \varphi\left(1-\exp -\frac{\varphi-\varphi_{0}}{\omega \tau}\right) \\
& =C_{F} \sin ^{1-x} \varphi\left(1-\exp -\frac{\varphi-\varphi_{0}}{\varphi_{\tau}}\right),
\end{aligned}
$$

where

$$
C_{F}=C_{k} a_{p} f_{z}^{1-x} .
$$

Functions (4) and (5) can be regarded as the transient basic functions of cutting force in milling. This is a phenomenological model where the physical content of time constant $\tau$ has not been explored yet. This shall be the subject of further research. Some features of the model are shown by Figs. 4 and 5. On the one hand, these figures present the characteristics of cutting force as a function of angle $\varphi$ (a), on the other hand, the actual undeformed thickness is shown as a function of $\sin \varphi(b)$.

As shown in Fig. 4, it can also be evidenced in down, up, and symmetric milling that the force converges on a curve that can be characterized by time constant $\tau \approx 0$ during the increase of the machined curve. Similar to turning, there is no transient phenomenon in this curve marked by a thin continuous line. It can also be seen from Fig. 4a that, due to the transient phenomenon, the maximum force does not develop at $\varphi=90^{\circ}$ but at angle $\varphi_{\max }$, which is larger. This can be determined from Eq. (5) based on the $\mathrm{dF} / \mathrm{dt}=0$ condition.

The transient nature of the specific cutting force gradually ceases in the phase after the maximum. This can be observed especially in Fig. 4a. As it can be seen, it is only in the $\varphi>90^{\circ}$ positions of the milling cutter that the transient effect lessens to a degree where the specific cutting force is mainly influenced by only the thickness of the removed layer. As a result of this, two constants, in this case $C_{k}$ and $x$, used in the Kienzle-formula, is usually not enough for the empirical calculation of the specific cutting

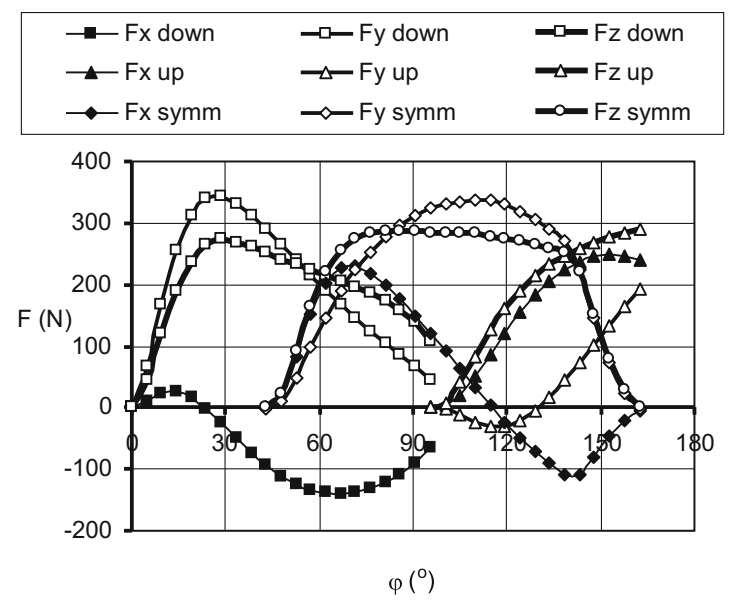

a)

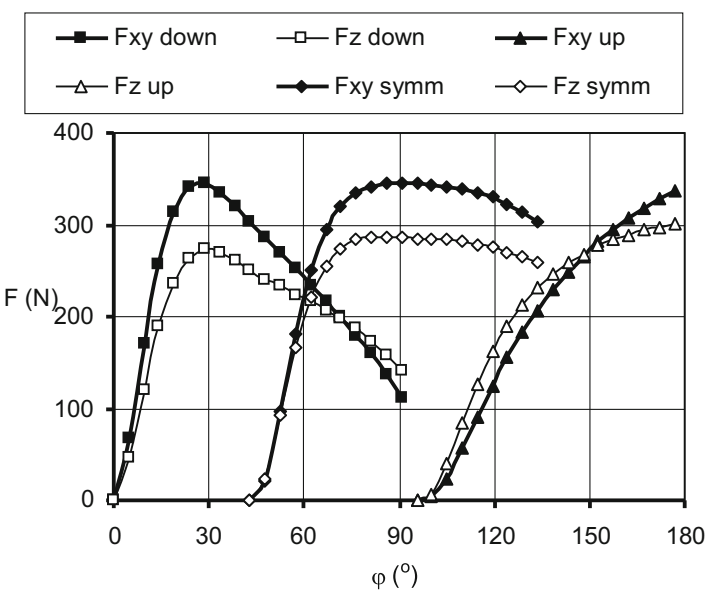

b)

Fig. 6 The data obtained by a three-component force measuring instrument. ( $\left.v=200 \mathrm{~m} / \mathrm{min}, f_{z}=0.4 \mathrm{~mm} / \mathrm{rev}\right)$ 


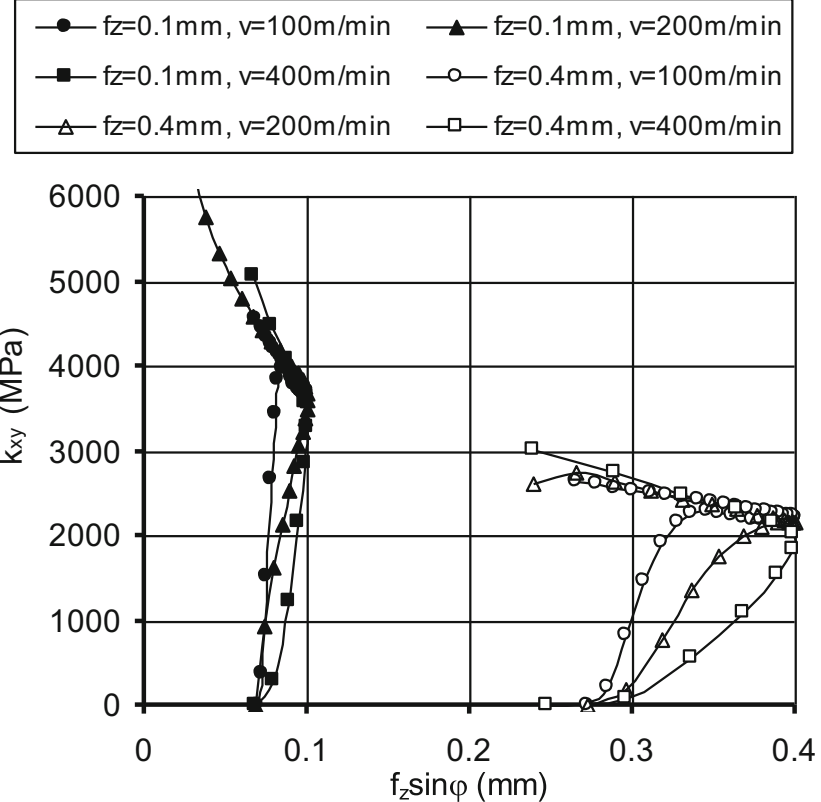

Fig. 7 The specific cutting force in symmetrical milling as a function of cutting speed and feed

force. $\tau$ time constant also needs to be determined. This is relatively simple in symmetrical milling. It is clear in Figs. $4 \mathrm{~b}$ and $5 \mathrm{~b}$ that the $\sin \varphi_{1}=\sin \left(\pi-\varphi_{1}\right)$ formula can be used at a chosen $\varphi_{1}>\varphi_{0}$ angle, and thus

$\frac{F\left(\pi-\varphi_{1}\right)}{F\left(\varphi_{1}\right)}=\Gamma=\frac{1-\exp -\frac{\pi-\varphi_{1}+\varphi_{0}}{\omega \tau}}{1-\exp ^{-} \frac{\varphi_{1}-\varphi_{0}}{\omega \tau}}$

Here, the transient constant $\Gamma$ can be determined by force measurement, then $\tau$ can be calculated with the numerical solution of Eq. (7).

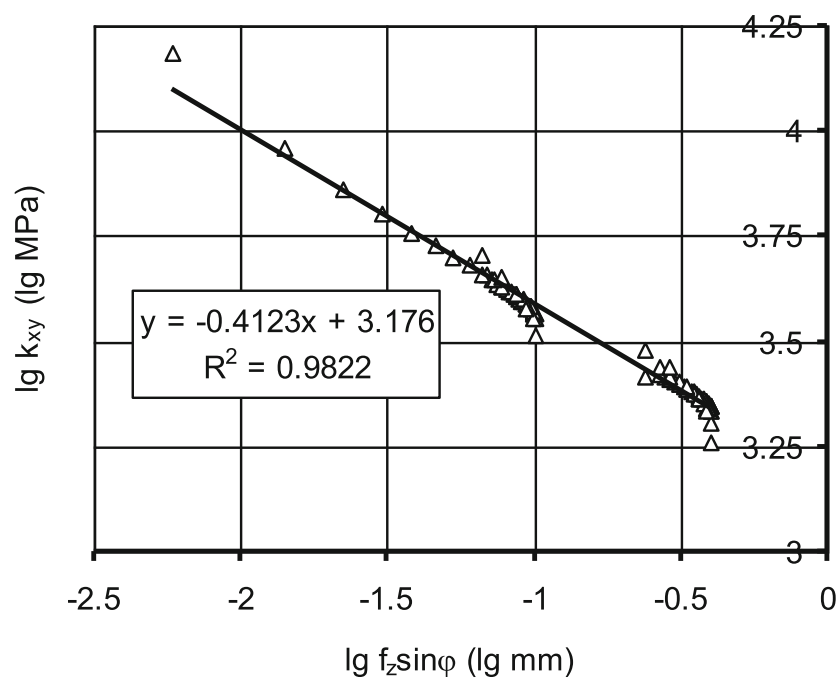

Fig. 8 The specific cutting force measured in the upper section of Fig. 7 on an lg-lg scale

\section{Measuring the cutting force}

The measurements were made in the laboratory of Institute of Manufacturing Science of the University of Miskolc, with a vertical machining center type PERFECT JET MCV-M8 (H).

Dynamometer: type Kistler 9257A three-component dynamometer, 3 Kistler 5011A charge amplifier, type National Instrument Compact DAQ-9171 four channel data acquisition unit, laptop. The measurement software was prepared in LabView programming language.

The workpiece was a normalized C45 unalloyed C-steel.

The type of the milling head: Sandvik R252.44-080027$15 \mathrm{M}$ face milling cutter, $D=80 \mathrm{~mm}$.

The type of the milling insert: Sandvik R215.4415T308M-WL GC4030

Edges: $\alpha=11^{\circ}, \gamma_{f}=20^{\circ}, \lambda_{s}=4^{\circ}, \kappa_{r}=90^{\circ}, \kappa_{r}{ }^{\prime}=1.5^{\circ}, r_{\varepsilon}=$ $0.8 \mathrm{~mm}$.

Technological data: $a_{p}=0.4 \mathrm{~mm}, f_{z}=0.1,0.4$, and $1.6 \mathrm{~mm} /$ rev, $v_{c}=100,200$, and $400 \mathrm{~m} / \mathrm{min}$.

The milling cutter cut with one edge so that the measurement of the cutting force should not be influenced by the other edges.

\section{The validation of the transient model of the milling force and discussion}

Chip removal occurs as a result of the distributed force system that develops on the contact surface between the tool and the workpiece and the chip. Based on the rules of statics, the
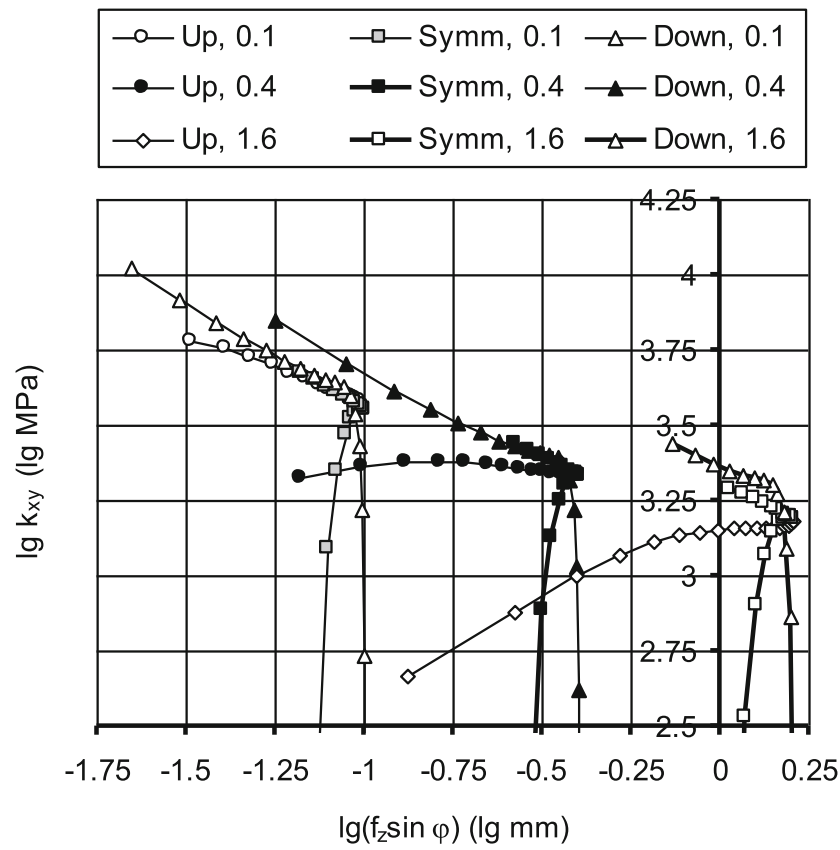

Fig. 9 The specific cutting force on an $\lg -\lg$ scale as a function of the current undeformed thickness (feed per tooth values; $f_{z}=0.1,0.4$ and $1.6 \mathrm{~mm} / \mathrm{rev})$ 


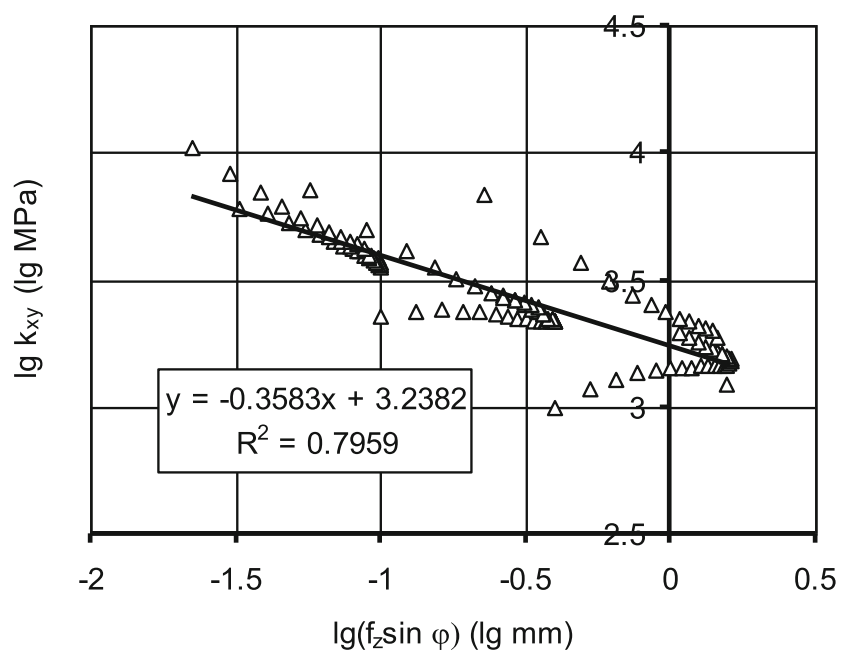

Fig. 10 The peak point of the curves of Fig. 9 and the regression line that shows the trend of functions

resultant of this system of forces is a force and a torque vector. Considering the relatively small size of the surfaces in contact, the torque is usually ignored in cutting theory, and it is only the resultant cutting force that is taken into consideration. Essentially, it is the force developing in the chip root that determines the process, and this is the amount of force that is necessary to start and maintain the process. The fact that main cutting force $F_{\mathrm{c}}$, thrust force $F_{\mathrm{h}}$, and passive force $F_{\mathrm{p}}$ are generally distinguished is a practical method for the study of forces and energy relationships. However, it must be acknowledged in the study of processes actually taking place that the resultant cutting force is the primary characteristic of the process. For the purposes of the impact assessment, it is practical to divide this into two components, namely $F_{x y}=\left(F_{x}{ }^{2}+\right.$ $\left.\left.F_{y}{ }^{2}\right)^{1 / 2}=F_{\mathrm{ch}}=F_{\mathrm{c}}{ }^{2}+\mathrm{F}_{\mathrm{h}}{ }^{2}\right)^{1 / 2}$ in the basic plane and passive force $F_{\mathrm{p}}$ at right angles to cutting speed v. From an energetic point of view, $F_{x y}$ is relevant from among these; therefore, validation was performed mainly with the analysis of $F_{x y}$

The results of force measurements with $f_{z}=0.4 \mathrm{~mm} / \mathrm{rev}$ feed are summarized in Fig. 6. Figure $6 \mathrm{~b}$ also shows the
$F_{x y}$ component. Such a series of measurements were performed with $f_{z}=0.1 \mathrm{~mm} / \mathrm{rev}$ and $f_{z}=1.6 \mathrm{~mm} / \mathrm{rev}$, as well as $f_{z}=0.4 \mathrm{~mm} / \mathrm{rev}$ feed with cutting speeds of $v=100$ and $400 \mathrm{~m} / \mathrm{min}$.

The nature of the curves shown in Fig. 6 corresponds to what can be seen in the basic function of the transient force model in Fig. 4b. This suggests a connection between the milling process examined by measurements and the assumed model.

When the model needs to be adjusted to the measurement results, the value of exponent $x$ is to be determined first in formulas (3)-(5). As the force measurement was performed by a three-component instrument, force $F_{x y}$ that develops in the basic plane of the tool can be calculated directly from components $F_{x}$ and $F_{y}$. Figure 7 shows the results of such measurements in symmetrical milling. Here, the values of specific cutting force $k_{x y}$ can be seen as a function of actual undeformed thickness of chip $h=f_{z} \sin \varphi$, which were measured in technological version $f_{z}=0.1$ and $0.4 \mathrm{~mm} / \mathrm{rev}$. This figure can be compared with the curve marked with a bold line in Fig. 5, and it can be stated that the nature of the curves is the same, which represents a qualitative justification of function (4). It can be clearly seen in Fig. $5 \mathrm{~b}$ that the transient characteristic actually ceases at the values of $\varphi$ that follow the peak point of the curve. So there the Kienzle-power function can be applied and exponent $x$ can be determined.

Figure 8 shows the normal procedure where measurement results are presented in an lg-lg scale coordinate system. Here, the data that were measured at $v=200 \mathrm{~m} / \mathrm{min}$ cutting speed and $f_{z}=0.1$ and $0.4 \mathrm{~mm} / \mathrm{rev}$ feed can be seen. As it can be seen, the regression line fits in well, the Pearson score is rather high at the line calculated for the data.

Figure 9 presents the measured values for the various methods of milling (up, symmetric, and down) and the three versions of $f_{z}$. The environment of the horizontal peak points of the curves is demonstrated by Fig. 10. As for the latter, the steepness of the line adjusted to the measurement results is nearly identical with the number shown in Fig. 8. Comparing
Fig. 11 The adjustment of the transient model to the measured values in symmetrical milling $\left(v=400 \mathrm{~m} / \mathrm{min}, f_{z}=0.4 \mathrm{~mm} / \mathrm{rev}\right.$, $\left.\tau_{\mathrm{av}}=3 \mu \mathrm{s}\right)$

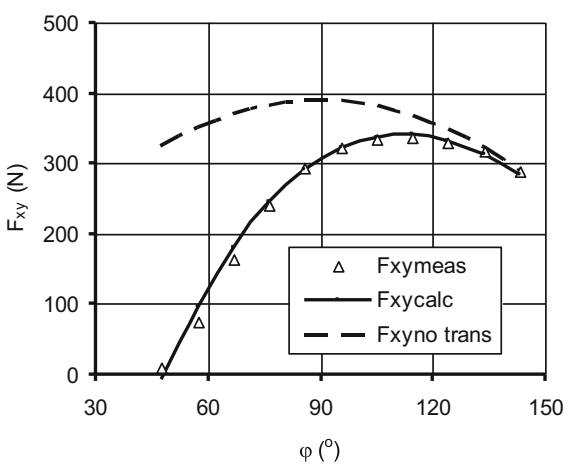

a)

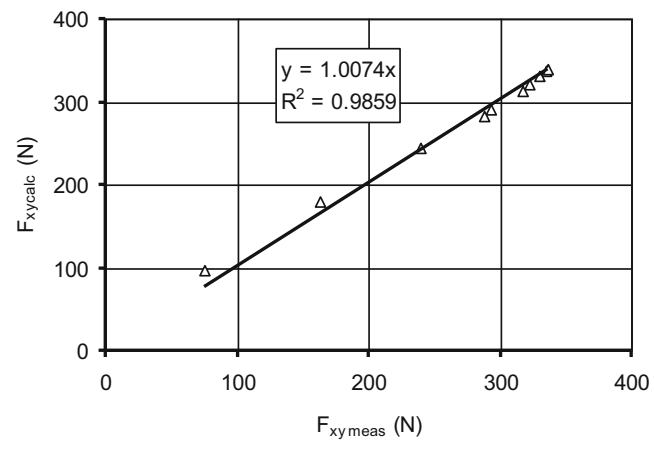

b) 
the results of several other measurements, it could be established that exponent value $x=0.4$ can be used in the data base of the series of experiments.

The $C_{F}, C_{k}$, and $\tau$ constants of formulas (4) and (5) can be determined if we know the value of $x$. This is possible by the application of Eq. (7) or by an iteration method, for which a concrete example is presented in Fig. 11. The symmetrical milling was carried out at a speed of $v=400 \mathrm{~m} / \mathrm{min}$ and $f_{z}=$ $0.4 \mathrm{~mm} / \mathrm{rev}$ feed, where forces $F_{x}, F_{y}$ were measured. $F_{x y \text {,meas }}$, which is also regarded as measured data, can be directly calculated from this. These are shown by data marked with triangles $(\Delta)$ in Fig. 11a. As the value of $x$ is already known, constants $C_{F}$ and $\tau_{\text {av }}$ (which is the average time constant of the transient milling process) need to be determined from formula (5). The target is that the $F_{x y, \text { calc }}$ calculated data series should fit in perfectly with the measured values. This can be achieved if, apart from steepness $\mathbf{a} \approx 1$, Pearson score $R^{2}$ approximates to the maximum value, nearly 1 , in the $y=a \cdot x$ formula of the regression line shown in Fig. 11b. The feasibility of this is demonstrated by Fig. $11 \mathrm{~b}$, where $C_{F}=400 \mathrm{~N}, \tau_{\mathrm{av}}=3 \mu \mathrm{s}$, and in these constants $a=1.0074, R^{2}=0.9859$. The calculations were made at cutting speeds $v=100$ and $200 \mathrm{~m} / \mathrm{min}$ and the results are shown by Table 1 and Fig. 10.

The measurement results presented in Fig. 11 can also be evaluated in another way. If there were not for the transient phenomenon, force $F_{x y}$ should be symmetrical to $\varphi=90^{\circ}$, as this is shown by the broken line. It can be clearly seen that the measured data and the model curve calculated from this data significantly deviate from this. It can also be observed that the measured data curve reaches its maximum at $\varphi_{\max }=111^{\circ}>$ $90^{\circ}$, and this also clearly suggests the presence of a transient effect (Fig. 12).

The impact of the cutting speed as a function of the undeformed thickness can also be seen in Fig. 13. If there were not for the transient effect, the measurement result should be the same in angle positions $90^{\circ}-\varphi$ and $90^{\circ}+\varphi$ of the milling cutter and we would not get a mapping curve shown in Fig. 5 b.

Formula (5) can be applied in the cases of force components $F_{x}, F_{y}$. Figure 14 shows the data measured in symmetrical milling and the model curves adjusted with formula (5). Matching can be regarded as satisfactory here as well.

Table 1 The constants of the measured and calculated data shown in Fig. $10\left(f_{z}=0.4 \mathrm{~mm} / \mathrm{rev}\right)$.

\begin{tabular}{lllll}
\hline $\mathrm{v}(\mathrm{m} / \mathrm{min})$ & $\mathrm{C}(\mathrm{N})$ & $\tau_{\mathrm{av}}(\mu \mathrm{s})$ & $a^{*}$ & $R^{2 * *}$ \\
\hline 100 & 353 & 2.6 & 0.9835 & 0.9649 \\
200 & 360 & 2.6 & 1.0023 & 0.9671 \\
400 & 400 & 3 & 1.0074 & 0.9859 \\
\hline
\end{tabular}

*The linear constant of regression line $y=a \cdot x$ shown in Fig. 11

**Pearson score

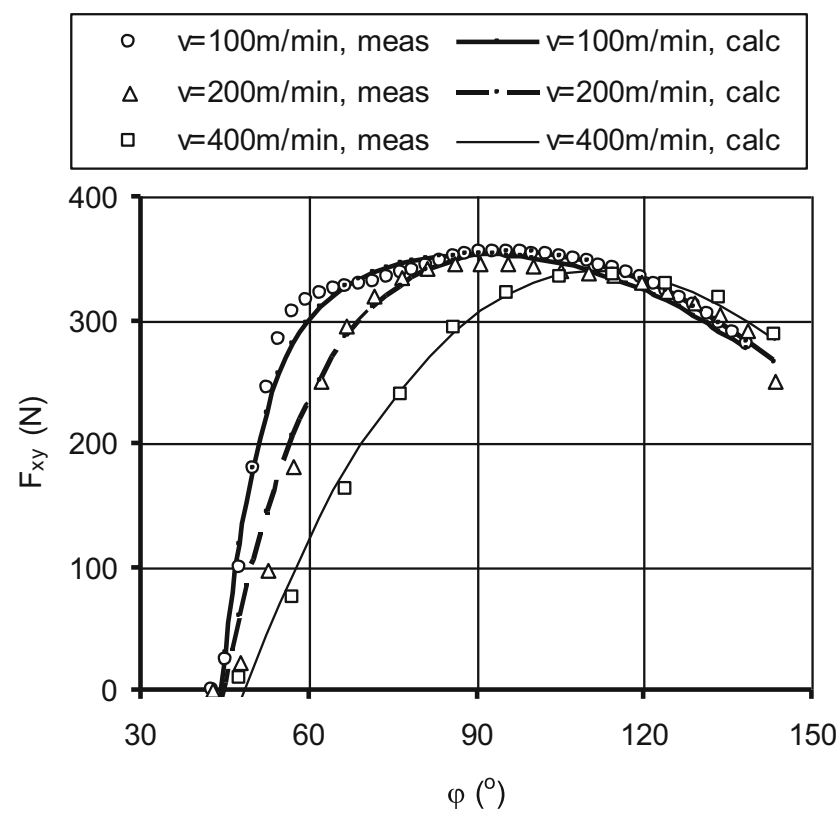

Fig. 12 The adjustment of the transient model to the measured values in symmetrical milling (Table 1)

Figure 15 presents the relationship of force components $F_{x}, F_{y}$, showing with broken line the characteristics where $\tau=0$ and which would occur if it were not for the transient phenomenon. There is a striking difference between the two curves.

Similar to symmetrical milling, formula (5) can also be applied in up and down milling (Fig. 16).

The three feeds applied at $a_{p}=0.4 \mathrm{~mm}=$ const depth of cut in the experimental programme also mean that the chip ratios, being $a_{p} / f_{z}: 4.0,1.0$, and 0.25 were significantly different in the three versions. It is important to consider that the shape of the cross section of the removed layer changes largely with the increase of the angle position of the milling cutter. In the case

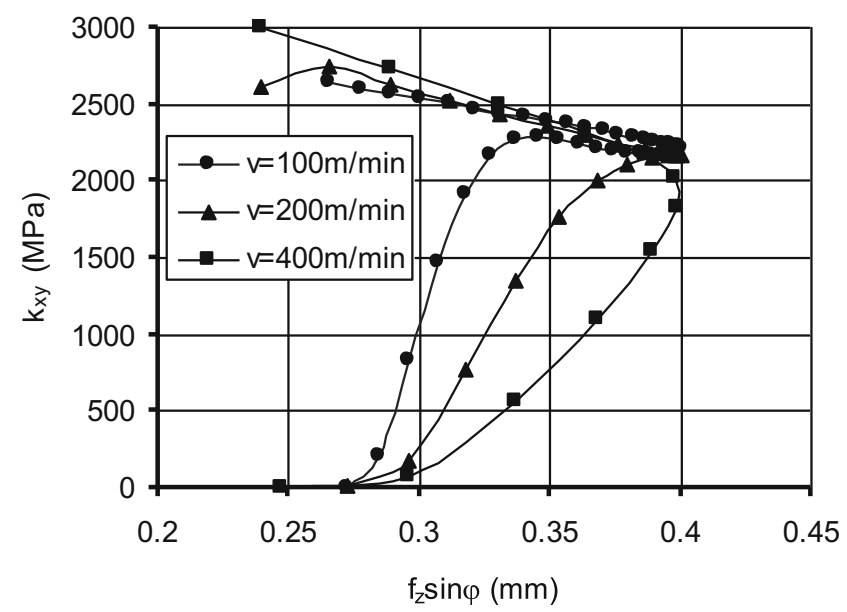

Fig. 13 Specific force $k_{x y}$ determined from measured forces $F_{x}$ and $F_{y}$ as a function of the undeformed thickness $\left(f_{z}=0.4 \mathrm{~mm}\right)$ 
Fig. 14 The matching of the transient model with the measured $F_{x}$ and $F_{y}$ cutting force values in symmetrical milling. $\left(v=200 \mathrm{~m} / \mathrm{min}, f_{z}=0.4 \mathrm{~mm} / \mathrm{rev}\right.$, $x=0.4)$

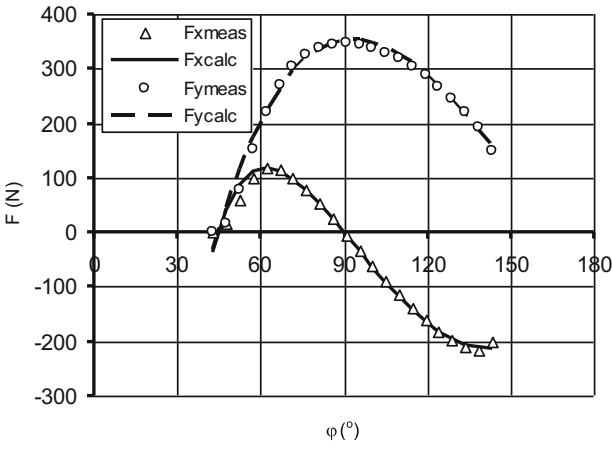

a)

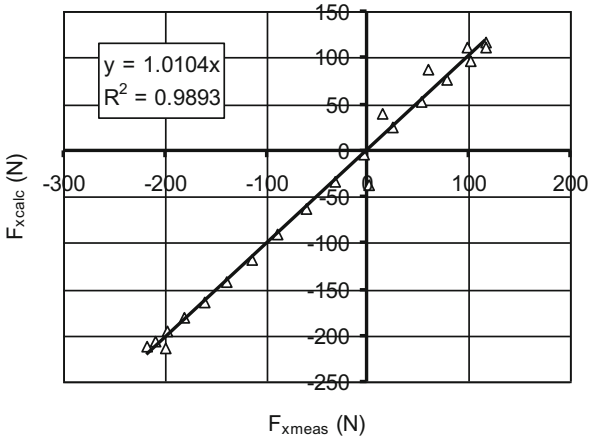

b) of the current $a_{p} / f_{z} \sin \varphi=0 . .4$ (if $f_{z}=0.1 \mathrm{~mm} / \mathrm{rev}$ ) chip ratio, it is really the undeformed thickness that is changing; however, the degree of change is considerably smaller and the nature of cutting is different as well if speed is $f_{z}=1.6 \mathrm{~mm}$ and chip ratio is $a_{p} / f_{z} \sin \varphi=0 \ldots 0.25$. In this version, the undeformed thickness is constant and the width of the layer is changing.

It is also an important factor if down milling or up milling is used. As for the former case, chip removal starts at the currently maximum thickness while a transient effect is experienced. On the other hand, it happens just the other way around. The transient effect is the strongest at the initial minimum thickness, then it gradually decreases while the removed thickness increases. Symmetrical milling combines these two tendencies because the undeformed thickness first increases, then decreases. Therefore, first the characteristics of up milling prevail, then the impacts of down milling apply. Consequently, the mechanism of chip formation is different. The $a_{p} / f_{z} \sin \varphi=1\left(f_{z}=0.4 \mathrm{~mm} / \mathrm{rev}\right)$ version is the typical case applicable to non-free cutting, which is also considerably different from the two other versions. The validity of the transient model had to be examined from the point of view of the various methods of milling under such circumstances. The

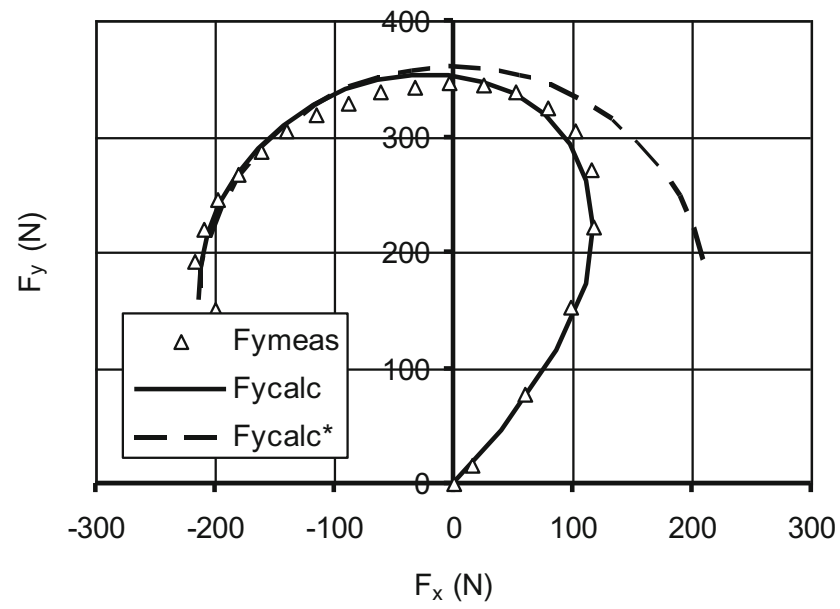

Fig. 15 The effect of the transient model on the relationship of the measured $F_{x}$ and $F_{y}$ cutting force values. $\left(F_{y \text { calc }} *: \tau \approx 0\right.$, data in Fig. 13) results are summarized in Fig. 17 and in Table 2. Generally, it can be stated that the model can be adjusted to the measured data well $\left(R^{2}>0.9\right)$ in spite of the fact that the shape and size of cross section can be rather different as shown previously. It is only in the case of down milling when the Pearson score is smaller $\left(R^{2} \approx 0.89\right)$, which is probably down to the characteristics listed above.

As it can be seen in the last two rows of Table 2, the basic function fits in with the measurement results only approximately in down milling. The data provided in the table was established based on the evaluation of the complete cutting phase. This data shall be regarded as average values that characterize the entire cutting phase. The more detailed examinations showed that $\tau_{\text {loc }}$ time constants calculated based on (7) for the various positions of angle $\varphi$ of the milling cutter decrease during the increase of $\varphi$ (Fig. 18), so $\varphi$ changes as a function of the time passed from the beginning of the cutting cycle. This is not surprising as it had to be acknowledged when creating the transient model that such a simple formula

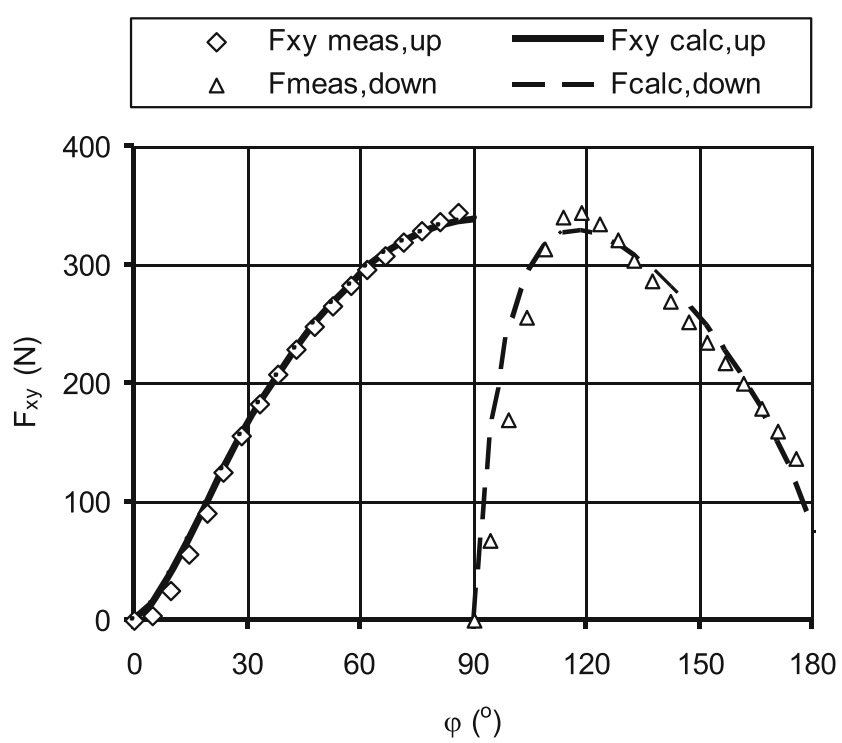

Fig. 16 The adjustment of the transient model to the measured cutting force values in up and down milling $\left(v=200 \mathrm{~m} / \mathrm{min}, f_{z}=0.4 \mathrm{~mm} / \mathrm{rev}, x=\right.$ 0.4 ; other data is shown in Table 2) 
Fig. 17 The verification of the transient model of specific cutting force $k_{x y}$ in the main methods of milling $\left(f_{z}=0.1 \mathrm{~mm} / \mathrm{rev}(\mathbf{a}), f_{z}=\right.$ $0.4 \mathrm{~mm} / \mathrm{rev}(\mathbf{b}), f_{z}=1.6 \mathrm{~mm} / \mathrm{rev}$ (c))

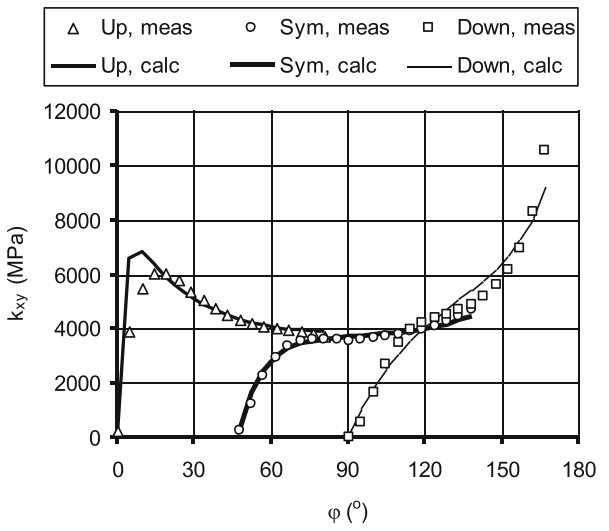

a)

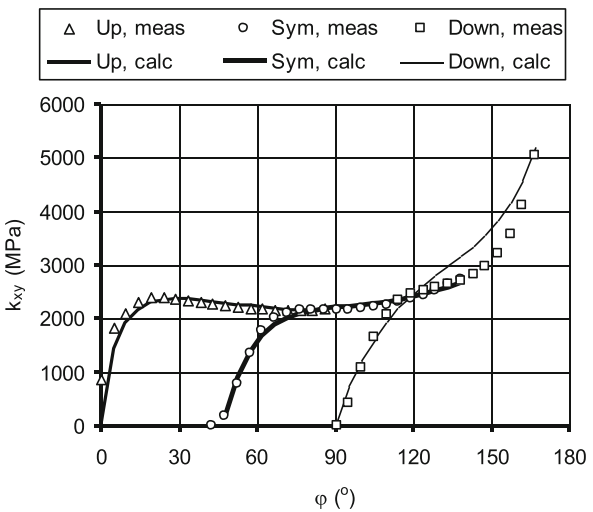

b)

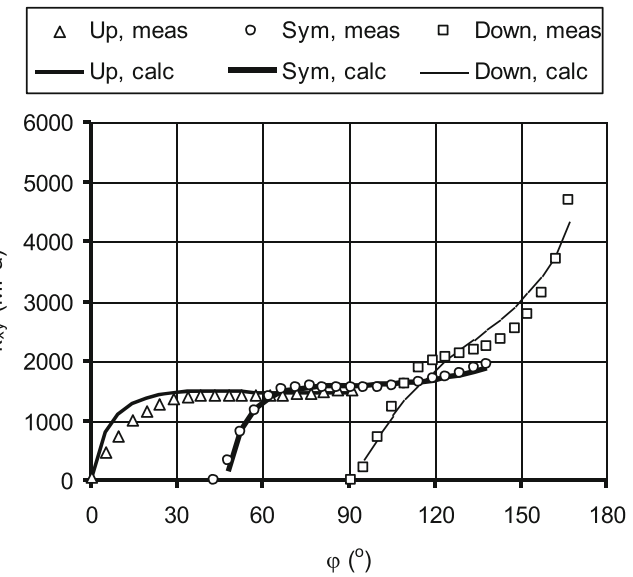

c)

Table 2 Adjustment of function (5) to the results of force measurements

\begin{tabular}{|c|c|c|c|c|c|c|}
\hline Milling & $f_{z}(\mathrm{~mm} / \mathrm{rev})$ & Force & $C_{F}(\mathrm{~N})$ & $\tau_{\mathrm{av}}(\mu \mathrm{s})$ & $a^{*}$ & $R^{2 * *}$ \\
\hline \multirow[t]{6}{*}{ Up } & \multirow[t]{2}{*}{0.1} & $F_{x y}$ & 154 & 1.0 & 1.0009 & 0.9927 \\
\hline & & $F_{z}$ & 205 & 1.2 & 1.0029 & 0.9613 \\
\hline & \multirow[t]{2}{*}{0.4} & $F_{x y}$ & 345 & 3.5 & 1.0061 & 0.9989 \\
\hline & & $F_{z}$ & 312 & 1.2 & 0.985 & 0.9939 \\
\hline & \multirow[t]{2}{*}{1.6} & $F_{x y}$ & 970 & 5.3 & 1.0024 & 0.9983 \\
\hline & & $F_{z}$ & 548 & 1.9 & 1.0091 & 0.9982 \\
\hline \multirow[t]{6}{*}{ Symm } & \multirow[t]{2}{*}{0.1} & $F_{x y}$ & 158 & 3.0 & 0.9949 & 0.9519 \\
\hline & & $F_{z}$ & 180 & 2.65 & 0.9909 & 0.9557 \\
\hline & \multirow[t]{2}{*}{0.4} & $F_{x y}$ & 368 & 2.7 & 1.0057 & 0.9472 \\
\hline & & $F_{z}$ & 310 & 2.5 & 1.0086 & 0.9525 \\
\hline & \multirow[t]{2}{*}{1.6} & $F_{x y}$ & 1020 & 1.8 & 0.9997 & 0.9872 \\
\hline & & $F_{z}$ & 573 & 1.8 & 0.999 & 0.9797 \\
\hline \multirow[t]{6}{*}{ Down } & \multirow[t]{2}{*}{0.1} & $F_{x y}$ & 198 & 4.4 & 1.0032 & 0.9262 \\
\hline & & $F_{z}$ & 265 & 5.5 & 1.0081 & 0.9362 \\
\hline & \multirow[t]{2}{*}{0.4} & $F_{x y}$ & 435 & 3.4 & 1.0486 & 0.9208 \\
\hline & & $F_{z}$ & 376 & 4.4 & 1.0059 & 0.9219 \\
\hline & \multirow[t]{2}{*}{1.6} & $F_{x y}$ & 1450 & 4.0 & 1.0153 & 0.8993 \\
\hline & & $F_{z}$ & 1600 & 5.0 & 1.0027 & 0.89 \\
\hline
\end{tabular}

*The constant of regression line $y=a \cdot x$

***earson score can only provide an approximate solution under manifold, complicated structural and kinematical conditions.

As the transient phenomenon mostly influences cutting force in the initial phase of cutting, the change of forces $F_{x y}$ and $F_{z}$ was examined separately in this initial phase. The results are summarized in Fig. 19. The criterion for determining

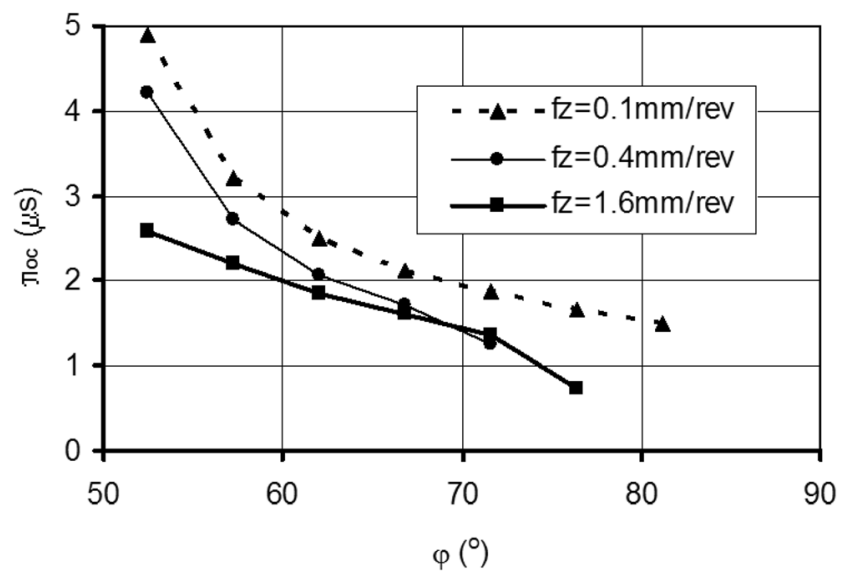

Fig. $18 \tau$ time constant as a function of the angle position in symmetrical milling $(v=200 \mathrm{~m} / \mathrm{min})$ 
the constants of function (5) was that the constant should be $0.99<\mathbf{a}<1.01$ and $R^{2}>0.99$ in the regression line $y=a \cdot x$ of the measured and calculated values. Besides meeting these strict criteria, it is completely obvious that the transient phenomenon greatly differs from the other milling methods in down milling. It is an especially striking phenomenon in Fig. 17b.

The fact that time constant $\tau$ continuously changes during the cutting process may lead to interesting conclusions regarding the causes of the transient phenomenon. This probably originates from the structural changes of the material that were mentioned in the introduction. However, this needs further research.

Understandably, the peak of the $F(\varphi)$ curve is important for practical technology. This force develops at the $\varphi_{\max }$ position of the milling cutter, which can be established from the measured data directly. As, based on Fig. 18, time constant $\tau$ is usually different in various $\varphi$ angles, the process is characterized by a local $\tau_{\text {loc,max }}$ time constant and a $\varphi_{\text {loc }, \tau}=\omega \tau_{\text {loc, } \max }$ angle in the environment of $\varphi_{\text {loc,max }}$. Assuming that the value of exponent $x$ has been determined, and the angle position $\varphi_{0}$ of the milling cutter is known at the beginning of cutting, there is a direct relationship between angles $\varphi_{\text {loc,max }}$ and $\varphi_{\text {loc, } \tau}$ pursuant to (5). This is presented by Fig. 20, where symmetrical milling is shown by a continuous line $\left(\varphi_{0}=43^{\circ}\right)$ and down milling by a broken line $\left(\varphi_{0}=90^{\circ}\right)$.

Table 3 includes the $\varphi=\varphi_{\text {av, } \max }$ values that could be established from the measurement series having a maximum (symmetric and down milling). The corresponding $\tau_{\text {av }}$ data come from Table 2.

The results marked in Fig. 20 show the different effect of the average and local time constant of the transient process and the scatter of the measurements. The fact that $\tau_{\mathrm{av}}$ and local time constant $\tau_{\text {loc,max }}$ at the maximum of the force differ can be understood based on Fig. 18. Moreover, the fact that this

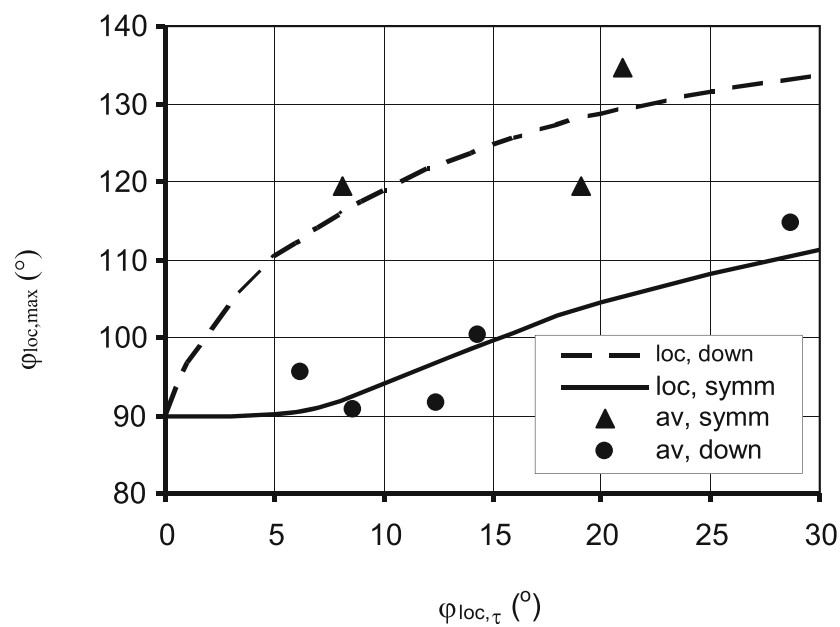

Fig. 20 Angle $\varphi_{\max }$ belonging to the maximum value of force $F_{x y}$ as a function of $\varphi_{\tau}=\omega \tau$ calculated from time constant $\tau$ (Table 3)

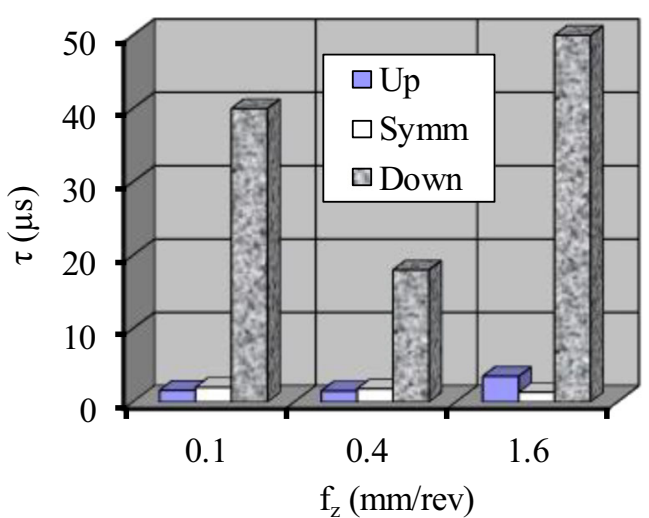

a)

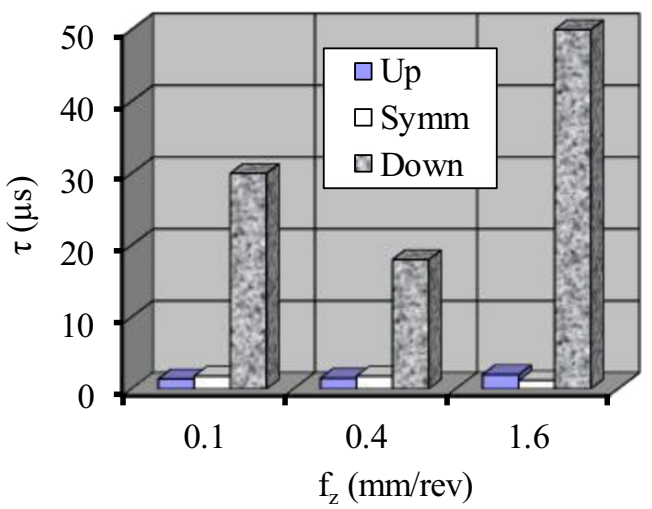

b)

Fig. 19 Time constant $\tau$ of the transient force in the initial phase of cutting in various milling methods $\mathrm{F}_{\mathrm{xy}}(\mathbf{a})$ and $\mathrm{F}_{\mathrm{z}}(\mathbf{b})$

difference scatters can be traced back to the complexity of the cutting process.

\section{The energy effect of the transient process}

The feature of the transient process that the force necessary for chip formation only gradually approximates the stationary status of the process is significant from an energy point of view. As it can be seen in Fig. 21 based on the data of the force measurement series, the specific power $\left(P_{\mathrm{c}}\right)$ need of chip formation reached the value which could be expected without the transient phenomenon, marked by the continuous line, in this symmetrical milling operation only at the end of the cycle. Although the difference rapidly decreases after the commencement of the process, it is significant. There is a similar situation in the case of down and up milling (Fig. 22).

This way, two opposite effects prevail in milling. One of them is the consequence of the well-known fact that the undeformed thickness of material continuously changes during machining. This considerably influences the specific cutting force, which significantly increases, often even due to rather small layer thickness. This is accompanied by the effect of the transient process shown above, as a result of which less energy 
Table $3 \varphi_{\max }$ angles determined with local and average time constant $\tau$

\begin{tabular}{|c|c|c|c|c|c|c|c|c|c|}
\hline Milling & $\begin{array}{l}v \\
(\mathrm{~m} / \mathrm{min})\end{array}$ & $\begin{array}{l}f_{z}(\mathrm{~mm} / \\
\text { rev })\end{array}$ & $\begin{array}{l}\varphi_{0} \\
\left(^{\circ}\right)\end{array}$ & $\begin{array}{l}\tau_{\mathrm{av}}{ }^{*} \\
(\mu \mathrm{s})\end{array}$ & $\begin{array}{l}\tau_{\text {loc,max }} \\
(\mu \mathrm{s})\end{array}$ & $\begin{array}{l}\varphi_{\mathrm{av}, \tau} \\
\left(^{\circ}\right)\end{array}$ & $\begin{array}{l}\varphi_{\text {loc, } \tau} \\
\left(^{\circ}\right)\end{array}$ & $\begin{array}{l}\varphi_{\text {loc,max }} \\
\left(^{\circ}\right)\end{array}$ & $\begin{array}{l}\varphi_{\mathrm{av}, \max } \\
\left(^{\circ}\right)\end{array}$ \\
\hline \multirow[t]{5}{*}{ Symm } & 100 & 0.4 & \multirow[t]{5}{*}{43} & 2.6 & 5.0 & 6.2 & 12 & 95.5 & 90.5 \\
\hline & \multirow[t]{3}{*}{200} & 0.1 & & 3.0 & 1.3 & 14.3 & 6 & 100.2 & 99.0 \\
\hline & & 0.4 & & 2.6 & 1.9 & 12.4 & 9 & 91.5 & 96.8 \\
\hline & & 1.6 & & 1.8 & 1.5 & 8.6 & 6.9 & 90.7 & 92.4 \\
\hline & 400 & 0.4 & & 3.0 & 3.8 & 28.7 & 36 & 114.6 & 110.4 \\
\hline \multirow[t]{3}{*}{ Down } & \multirow[t]{3}{*}{200} & 0.1 & \multirow[t]{3}{*}{90} & 4.4 & 6.7 & 21.0 & 32 & 134.7 & 131.0 \\
\hline & & 0.4 & & 1.7 & 1.5 & 8.1 & 10 & 119.4 & 115.9 \\
\hline & & 1.6 & & 4.0 & 1.5 & 19.1 & 10 & 119.4 & 128.0 \\
\hline
\end{tabular}

*See Table 2, $x=0.4$

is necessary for chip formation in the initial phase than in continuous cutting. So, this double effect jointly determines the energy need of the cutting of a given amount of material.

It is broadly known that the specific energy need of cutting is an important technological and economic feature, which is largely influenced by various technological parameters. Figure 23 presents the specific energy (E) need in the three main methods of milling. It transpires that the energy necessary for chip formation is rather different in the various methods of milling. From an energy point of view, symmetrical milling is the most advantageous based on the experiments conducted in this project. The undeformed thickness in up milling starts from zero in principle but actually from the removable minimum value. This means that the specific cutting force is high at the initial phase of the cutting cycle. There is a similar situation in the case of down milling, although this phenomenon is less intensive due to the transient effect there. Naturally, these statements only concern the cases where $B<$ $D$, i.e., the width of the workpiece is smaller than the diameter of the milling cutter. The value determined by calculation, which would characterize the cutting operations without the

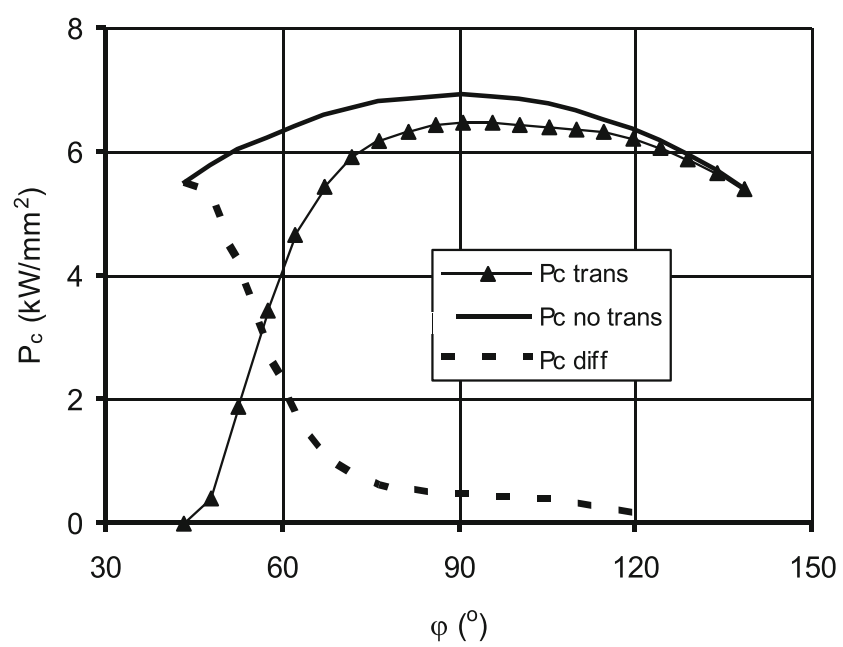

Fig. 21 The transient specific power need in symmetrical milling ( $D=$ $80 \mathrm{~mm}, B=58 \mathrm{~mm}, f_{z}=0.4 \mathrm{~mm} / \mathrm{rev}, v=200 \mathrm{~m} / \mathrm{min}$ ) transient effect, is also shown in accordance with the Figs. 21 and 22. Here, both effects mentioned above can be observed. On the one hand, it can be seen that the specific energy need is smaller in symmetrical milling because the same amount of material is removed with the cutting of a thicker layer. On the other hand, the transient effect is also significant in all the three versions.

Karpuschewski and Batt [40] pointed out that cutting ratio $a_{p} / f_{z}$ strongly influences the cutting force. The smaller this ratio is, the better the shape of the removed diameter becomes and consequently the cutting force decreases. This effect occurs in a complex way in milling. It is practical to differentiate current cutting ratio $a_{p} / f_{z} \sin \varphi$ belonging to the angle position $\varphi$ of the milling cutter, which changes continuously, from cutting ratio $a_{p} / f_{z}$, which can be regarded as specific. It has been broadly known for a long time that the specific cutting force decreases in parallel to the increase of the undeformed thickness. Besides, it must also be considered that large feed $f_{z}$ modifies the characteristics of chip formation. It is not the thickness but the width of the band that decreases during

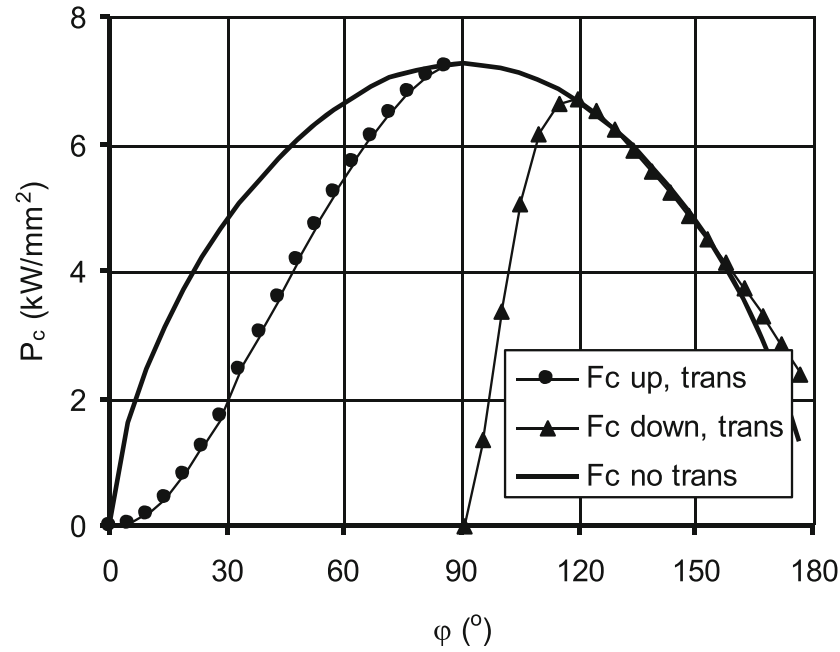

Fig. 22 The transient specific power need in down and up milling ( $D=$ $80 \mathrm{~mm}, B=58 \mathrm{~mm}, f_{z}=0.4 \mathrm{~mm} / \mathrm{rev}, v=200 \mathrm{~m} / \mathrm{min}$ ) 


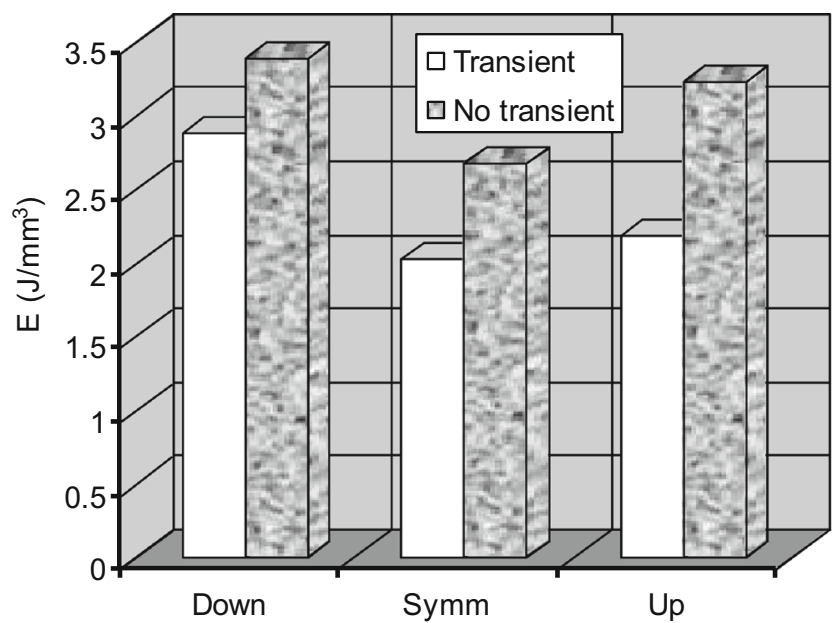

Fig. 23 The specific energy need of chip formation in various milling methods ( $v=200 \mathrm{~m} / \mathrm{min}, a_{p}=0.4 \mathrm{~mm}, f_{z}=0.4 \mathrm{~mm} / \mathrm{rev}$ )

the turn of the milling cutter, which also has a positive effect. The energy consequence of this complex effect is shown in Fig. 24. The transient effect can be observed as well.

Figure 25 shows the effect of cutting speed. In addition to the above, a further effect of the transient phenomenon can be observed. Obviously, the specific energy need has a maximum. It is broadly known that cutting force generally decreases if speed increases; however, this is preceded by a growing phase that is also the cause of the transient effect. This is in line with the conclusion made by Salomon [17] claiming that cutting temperature only increases up to a certain limit during the increase of speed, then it starts to decrease. This was confirmed by the examination of Pálmai [21]. There is no proven direct connection between the specific energy need of cutting and the temperature developing in the chip root, as the energy need characterizes the process, while the temperature characterizes the condition of the chip root in a selected moment. The analogy, however, is evident.

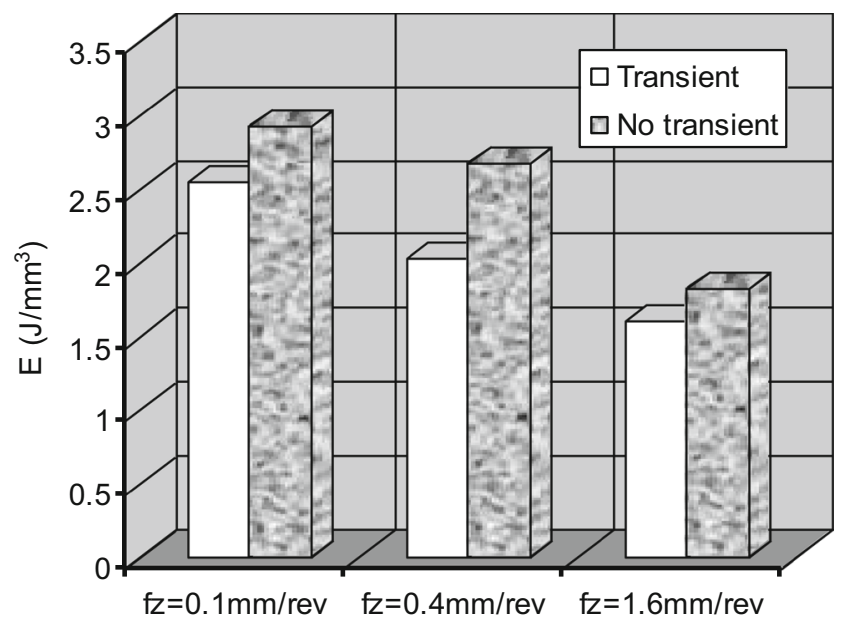

Fig. 24 The specific energy need of chip formation in various feeds (symm, $v=200 \mathrm{~m} / \mathrm{min}, a_{p}=0.4 \mathrm{~mm}$ )

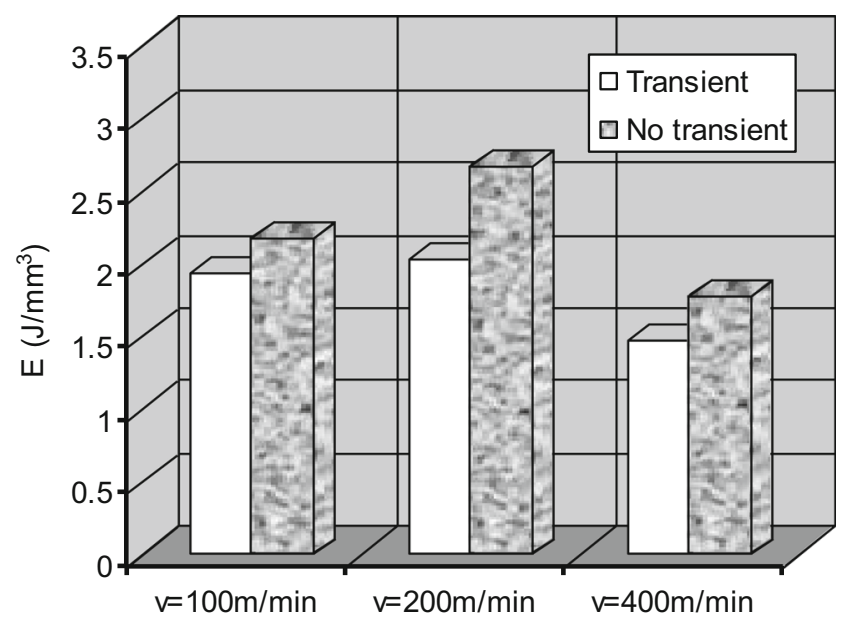

Fig. 25 The specific energy need of chip formation in various cutting speeds (symm, $a_{p}=0.4 \mathrm{~mm}, f_{z}=0.4 \mathrm{~mm} / \mathrm{rev}$ )

The results of force measurements enabled the energy comparison of milling and turning. It is assumed that if a chosen $f_{z}$ feed was applied in turning, the specific cutting force that could be measured in the environment of $\varphi=90^{\circ}$ in milling would develop. The specific energy need of turning can be calculated by this, which is shown by Fig. 26 .

It is understandable that the energy need is smaller in the case of greater feed and the beneficial effect of the decrease of cutting ratio $a_{p} / f_{z}$, which was shown by Karpuschewski [40]. The same can be established for milling. The new piece of information is that the relationship of energy need in the two methods of cutting can vary. It can be seen that milling is more advantageous at $f_{z}=0.1 \mathrm{~mm} / \mathrm{rev}$ feed; however, this changes at larger feeds. All in all, it can be established that the energy need of turning and the symmetrical milling presented herein are approximately the same due to the opposite effect of the two phenomena mentioned, i.e., the change of band thickness and the transient phenomenon.

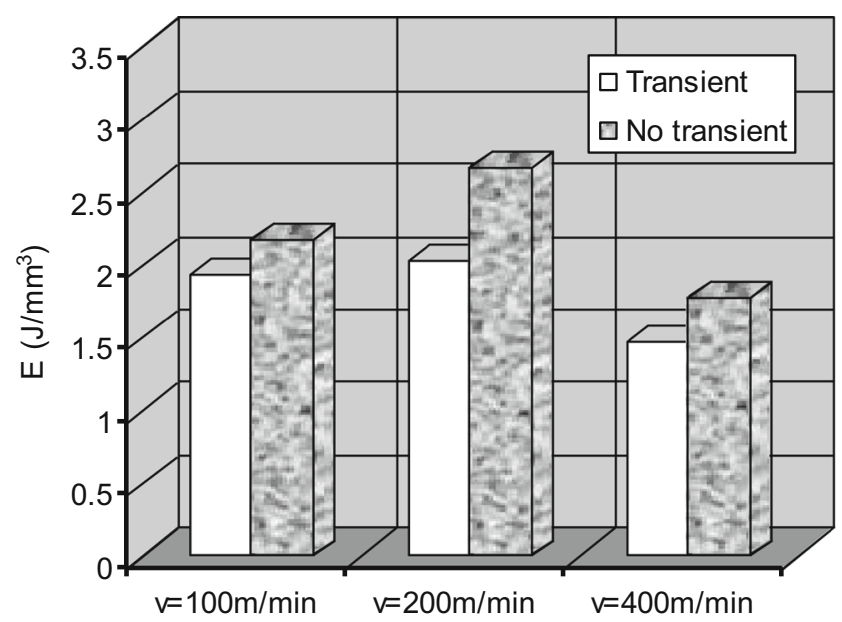

Fig. 26 The specific energy necessary for chip formation compared with turning theoretically (symm, $v=200 \mathrm{~m} / \mathrm{min}, a_{p}=0.4 \mathrm{~mm}$ ) 


\section{Summary}

The measurement and calculation of cutting forces in manufacturing has been studied by researchers of cutting theory for a long time. Turning removing a permanent diameter was studied for many years, but lately more and more attention has been given to the cutting of a changing cross section, i.e., milling. This paper gives an account of the research whose objective was to examine the transient processes assumed in milling. A model that describes the actual cutting force in short-time interrupted cutting was elaborated for this. The hypothesis was that the thermodynamic processes of deformation in the chip root are time consuming; therefore, the cutting force reaches the stationary status during a finite time. A model function where the usual Kienzle function was supplemented with an exponential part was applied in the qualitative description of the assumed transient process.

The force measurements were performed during the milling of normalized C45 steel. There was only one insert in the milling tool so that the process changing quickly in time could be examined better. The symmetrical, down and up milling were conducted with $a_{p}=0.4 \mathrm{~mm}$ depth of cut, $f_{z}=0.1,0.4$ and $1.6 \mathrm{~mm} / \mathrm{rev}$ feed, and $v_{c}=100,200$, and $400 \mathrm{~m} / \mathrm{min}$ cutting speeds. The diameter of the milling cutter was $D=$ $80 \mathrm{~mm}$, the width of the workpiece was $B=58 \mathrm{~mm}$.

Based on the experiment, the following conclusions can be drawn:

It was clearly proven that the assumed transient phenomenon does exist and it can be described approximately by an exponential function, which shows the speed of the process by a time constant $\tau$. The deformation of the material in cutting is the result of such complicated processes that can be described by the exponential function only approximately; time constant $\tau$ changes during the process. Nevertheless, an average time constant $\tau_{\mathrm{av}}$ can be determined for the whole cutting cycle. This time constant characterizes the cycle well.

The model function fit in well with the measured $F_{x y}$ forces and $k_{x y}$ specific cutting forces determined based on the forces. The Pearson score of the correlation was $R^{2}>0.9$, or often even higher than 0.95 .

The traditional Kienzle power function of the specific cutting force in milling cannot be used because it fails to consider the transient process. However, it can be applied well if supplemented with an exponential part.

The transient phenomenon in milling leads to the consequence that the specific energy need of the material's cutting is smaller than in the case of a stationary process.

There is a considerable difference between the energy processes of the removal of the chip root in the case of cutting with varying specific cutting ratio $a_{p} / f_{z}$. If cutting ratio $a_{p} / f_{z}$ is smaller, the specific energy use is also smaller.

The fact that the specific energy need of cutting based on measurements is smaller in symmetrical milling than in down or up milling, it can also be attributed to the impact of the transient phenomenon.

If milling is compared with turning from an energy point of view, it can be concluded that the specific energy use is nearly the same because the opposite effects mostly offset each other.

The physical content of time constant $\tau$ has not been explored in depth yet in the presented phenomenological model of the cutting force in milling. Further research is required in this respect, which may make the model more precise.

Acknowledgements Open access funding provided by University of Miskolc (ME).

Funding information The authors greatly appreciate the (financial) support of the National Research, Development and Innovation OfficeNKFIH (No. Of Agreement: OTKA K 116876), Hungary

Open Access This article is distributed under the terms of the Creative Commons Attribution 4.0 International License (http:// creativecommons.org/licenses/by/4.0/), which permits unrestricted use, distribution, and reproduction in any medium, provided you give appropriate credit to the original author(s) and the source, provide a link to the Creative Commons license, and indicate if changes were made.

\section{References}

1. Bayard O (2000) Investigation of the verification techniques for modelling turning processes. Royal Institute of Technology, Dept. Material Processing, Production Engineering, Stockholm

2. Komanduri R (1993) Machining and grinding: a historical review of the classical papers. Appl Mech Rev 46(3):80-132

3. Kundrák J, Gyáni K, Tolvaj B, Pálmai Z, Tóth R (2017) Thermomechanical modelling of hard turning: a comptational fluid dynamics approach, simulation modelling practice and theory, vol 70, pp 52-64

4. Cheng K (ed) (2008) Machining dynamics: theory, applications and practices. Springer, London

5. Ezugwu EO, Sales WF, Landre J (2008) Machining dynamics in turning processes. In: Cheng K (ed) Machining dynamics: theory, applications and practices. Springer, London, pp 151-166

6. Liu X (2008) Machining dynamics in milling processes. In: Cheng $\mathrm{K}$ (ed) Machining dynamics: theory, applications and practices. Springer, London, pp 167-231

7. Altintas Y (2012) Manufacturing automation: metal cutting mechanics, machine tool vibrations and $\mathrm{CNC}$ design, 2nd Edition. Cambridge University Press

8. Turkovich BF (1967) Dislocation theory of share stress and strain rate in metal cutting, Advanced in Machine Tool Design and Research, Proceedings of the 8th international M.T.D.R. conference (incorporating the 2nd international CIRP production engineering research conference), University of Manchester, Institute of Science and Technology, pp. 531-542

9. Black JT (1971) On the fundamental mechanism of large strain plastic deformation, electron microscopy of metal cutting chips. J Eng Ind 93:507-526

10. Black JT (1972) Shear front-lamella structure in large strain plastic deformation processes. J Eng Ind 94:307-316

11. Ramalingam S, Black JT (1973) An electronmicroscopy study of chip formation. Metallurgical Transactions 4:1103-1112 
12. Black JT (1979) Flow stress model in metal cutting. Journal of Engineering for Industry 101:403-415

13. Lin ZC, Chen ZD, Hua C (2007) Establishment of a cutting force model and study of the stress-strain distribution in nano-scale copper material orthogonal cutting. Int J Adv Manuf Technol 33:425435

14. Li QJ, Li J, Shan ZW, Ma E (2016) Strongly correlated breeding of high-speed dislocations. Acta Mater 119:229-241

15. Lüthy H, Whitte RA (1979) Grain boundary sliding deformation mechanism maps. Mater Sci Eng 39:211-216

16. Zerilli FJ, Armstrong RA (1987) Dislocation-mechanics-based constitutive relations for material dynamics calculations. Journal of Applied Physics 61(5):1816-1825

17. Salomon C (1929) Schnittdruck- und Schneidtemperatur Erscheinungen an der Werkzeugschneide, Die Werkzeugmaschine, Zeitschrift für Metallbearbeitung und Maschinenbau, 33. Jahrg. Heft 23. pp. 477-496

18. Longbottom JM, Lanham JD (2006) A review of research related to Salomon's hypothesis on cutting speeds and temperatures. Int J Mach Tools Manuf 46:1740-1747

19. Pálmai Z (1987) Cutting temperature in intermittent cutting. Int J Mach Tools Manuf 27(2):261-274

20. Pálmai Z (2017) Mathematical analysis of transient temperature changes in the chip root during milling. Int $\mathrm{J}$ Adv Manuf Technol 91(9-12):4219-4232

21. Crookall JR, Raine T (1971) Cutting forces, temperatures and surface characteristics for CIRP nickel-chrome steels. Ann CIRP XVIV:183-189

22. Zheng HQ, Li XP, Wong YS, Nee AYC (1999) Theoretical modelling and simulation of cutting forces in face milling with cutter runout. Int J Mach Tools Manuf 39:2003-2018

23. Lazoglu I, Buyukhatipoglu K, Kratz K, Klocke F (2006) Forces and temperatures in hard turning. Mach Sci Technol 10:157-179

24. Fan Y, Zheng M, Zhang D, Yang S, Cheng M (2014) Static and dynamic characteristic of cutting force when high-efficiency cutting Ti-6Al-4V. Adv Mater Res 305:122-128

25. Thandra SK, Choudhury SK (2010) Effect of cutting parameters on cutting force, surface finish and tool wear in hot machining. Int $\mathrm{J}$ Mach Mach Mater 7(3-4):260-273

26. Aurich JC (2006) 3D finite element modelling of segmented chip formation. Ann CIRP 55:47-50

27. Sato M, Tamura N, Tanaka H (Apr. 2011) Temperature variation in the cutting tool in end milling. J Manuf Sci Eng 133:021005-0211-6
28. Cui X, Zhao B, Jino F, Zheng J (2016) Chip formation and its effects on cutting force, tool temperature, tool stress, and cutting edge wear in high- and ultra-high-speed milling. Int J Adv Manuf Technol 83:55-65

29. Ghani MU, Abukhshim NA, Sheikh MA (2008) An investigation of heat partition and tool wear in hard turning of $\mathrm{H} 13$ tool steel with CBN cutting tools. Int J Adv Manuf Technol 39:874-888

30. Suresh R, Basavarajappa S, Samuel GL (2012) Predictive modelling of cutting forces and tool wear in hard turning using response surface methodology. Proc Eng 38:73-81

31. Li Z, Wang G, He G (2017) Milling tool wear state recognition based on partitioning around medoids (PAM) clustering. Int J Adv Manuf Technol 88:1203-1213

32. Zheng G, Zhao J, Song X, Cheng X (2014) A fractal analysis of cutting forces in simulation and experiment. Key Eng Mater 589590:122-127

33. Zhang S, Li J, Lv H, Chen W (2014) An experimental investigation of cutting forces in hard milling of H13 steel under different cooling/lubrication conditions. Key Eng Mater 589-590:13-18

34. Zener C, Holomon JH (Jan) Effect of strain rate upon plastic flow of steel. J Appl Phys 15, 1944:22-32

35. Zener C, Hollomon JH (1946) Problems in non elastic deformation of metals. J Appl Phys 17(2):69-82

36. Ashby MF (1972) A first report on deformation-mechanism maps. Acta Metall 20:887-897

37. Leslie WC (1961) The physical metallurgy of steels. McGraw-Hill Book Company, London

38. Kalhori V, Wedberg D, Lindgren L-E (2010) Simulation of mechanical cutting using a physical based material model. International Journal of Material Forming 3(Supp. 1):511-514

39. Li Q, Gong Y-d, Sun Y, Liu Y, Liang C-x (2018) Milling performance optimization of DD5 Ni-based single-crystal superalloy. Int J Adv Manuf Technol 94(5-8):2875-2894

40. Karpuschewski B, Batt S (2007) Improvement of dynamic properties in milling by integrated stepped cutting. Ann CIRP 56(1):85-88

Publisher's note Springer Nature remains neutral with regard to jurisdictional claims in published maps and institutional affiliations. 